\section{Public Health Genomics}

Public Health Genomics 2011;14:26-34

DOI: $\underline{10.1159 / 000294151}$
Received: March 19, 2009

Accepted after revision: October 5, 2009 Published online: April 8, 2010

\title{
Risk Perceptions and Family History of Lung Cancer: Differences by Smoking Status
}

\author{
L.S. Chen ${ }^{a} \quad$ K.A. Kaphingst ${ }^{b}$ \\ aDepartment of Health and Kinesiology, Texas A\&M University, College Station, Tex., and \\ ${ }^{b}$ Social and Behavioral Research Branch, National Human Genome Research Institute, Bethesda, Md., USA
}

\section{Key Words}

Family history $\cdot$ Lung cancer $\cdot$ Risk perceptions $\cdot$ Smoking

\begin{abstract}
Background: Individuals with a family history of lung cancer have a two- to threefold increased risk for developing this disease. Family history information may be useful in lung cancer prevention and control approaches, but research is needed regarding how individuals interpret this information. This study examined associations between lung cancer family history and individuals' risk perceptions, based on smoking status. Methods: Data were analyzed from 5,105 U.S. adult respondents to the 2005 Health Information National Trends Survey, which was conducted with a nationally representative sample. Results: In multivariate models, family history of lung cancer was positively associated with absolute and relative risk perceptions among all respondents $(\beta=0.60,95 \% \mathrm{Cl}=0.33-0.87$ and $\beta=0.17,95 \% \mathrm{Cl}=0.04-0.31$, respectively) and among never smokers $(\beta=0.40,95 \% \mathrm{Cl}=$ $0.14-0.67$ and $\beta=0.14,95 \% \mathrm{Cl}=0.01-0.27$, respectively). However, these associations were not significant for current and former smokers. Conclusion: While perceived risk was associated with family history of lung cancer among never smokers, this was not true for other smoking status subgroups. Therefore, former and current smokers might not re-
\end{abstract}

spond as intended to cancer prevention or cessation messages tailored based on family history. The results suggest directions for future research into how to best integrate family history information into prevention and control efforts.

Copyright $\odot 2010$ S. Karger AG, Basel

\section{Introduction}

Lung cancer is the primary cause of cancer death in the United States. It claims more lives than the next 3 most common cancers (i.e. colon, breast and prostate cancer) combined. The current age-adjusted death rate is 62.0 per 100,000 for males and 45.9 per 100,000 for females. Moreover, the survival rate of lung cancer is relatively poor. The expected 5 -year survival rate for lung cancer patients (16\%) is much lower than that for colon, breast and prostate cancers $(64.1 \%, 88.5 \%$ and $99.9 \%$, respectively) [1].

Health professionals have not generally focused on the significance of family history as a risk factor for lung cancer, likely because nearly $90 \%$ of lung cancer deaths are attributed to cigarette smoking [1]. However, family history can provide important information about cancer risk, as it captures shared environmental, behavioral and genetic risk within the family unit [2]. More than that,

\section{KARGER}

Fax +41613061234

E-Mail karger@karger.ch

www.karger.com (c) 2010 S. Karger AG, Basel

Accessible online at: www.karger.com/phg
Lei-Shih Chen

Department of Health and Kinesiology

Texas A\&M University

College Station, TX 77843-4243 (USA)

Tel. +1 979862 2912, Fax +1 979847 8987, E-Mail lace@hlkn.tamu.edu 
existing research clearly indicates that, regardless of smoking status, individuals with a family history of lung cancer have a two- to threefold increased risk for developing this disease $[3,4]$. Thus, the role of family history in lung cancer risk should not be overlooked.

Family history could serve as the basis for easily accessible and currently available public health genomics approaches or, in other words, approaches that integrate genomic information and technologies into lung cancer prevention and intervention programs [2]. A family history focus provides a number of advantages for such programs. Although numerous smoking cessation programs have been implemented to reduce the overall burden of lung cancer, approximately one-fifth of U.S. adults were current smokers in 2007 [5]. It is possible that focusing on family history as well as tobacco-related behaviors might increase the effectiveness of lung cancer control programs. While genetic susceptibility testing for lung cancer has been offered in a few smoking cessation studies [6-10], this testing is generally only available in a research context. In contrast, family history can be considered now for integration into smoking cessation programs [2].

One critical role that has been suggested for family history information in disease prevention interventions is as an initial screening tool to classify an individual's risk level for receiving specific prevention recommendations, treatment or subsequent genetic tests [11]. For example, in the context of lung cancer, family history information could be used as a marker to identify high-risk individuals who have a positive family history of lung cancer in order to detect lung diseases earlier $[3,4]$. Similarly, family history information could be used in conjunction with efforts to prevent higher-risk populations from being exposed to various lung cancer-related risk factors, such as environmental tobacco smoke, occupational hazards or radon. Family history information could also be used in targeting smoking prevention programs to adolescents at increased lung cancer risk due to their family history.

Research has shown that family history of lung cancer is linked to objective risk of developing lung cancer [12]; however, few studies have explored how this information might be integrated into lung cancer prevention and intervention efforts. In particular, although family historybased disease prevention initiatives are often intended to stratify individuals by risk level [11], it is not clear that lay individuals will interpret family history of lung cancer as affecting their disease risk. This could lead to misinterpretations of prevention and intervention messages based on family history information, subsequently impacting the effectiveness of prevention initiatives.
Furthermore, health behavioral theories, such as the Health Belief Model [13], Self-Regulatory Model [14], risk perception attitude framework [15], Protection Motivation Theory [16], and Theory of Reasoned Action [17], all suggest that subjective risk perception is a theoretically important predictor of protective health behavior adoption and adherence, although other emotion-based (or parallel processing) theories [18] posit different pathways through which human behavior could shape risk perceptions. It is therefore critical to examine the underlying assumption of family history-based prevention initiatives that people with a cancer family history perceive themselves to be at increased risk. To the best of our knowledge, however, there have been no studies examining this relationship for lung cancer. For other types of cancers, the relationship between family history and subjective risk perception of developing cancer remains unclear and may differ by cancer [19-24].

We addressed this issue with an analysis of data from the 2005 Health Information National Trends Survey (HINTS) wave, which was conducted with a large and nationally representative sample of U.S. adults. We examined the correlations between self-reported lung cancer family history and 2 subjective risk indexes - absolute risk and relative (comparative) risk perceptions. The former index assesses individuals' perceived likelihood of developing a certain disease; the latter assesses perceived likelihood of developing a certain disease compared to other people [25]. Because risk perceptions are subjective, the psychological variable self-reported family history, which represents participants' perceptions of their family history as linked to their knowledge, beliefs, culture, personal experience, and behavior, is a meaningful measure to explore in examining the relationship between family history and perceived risk $[20,26]$.

Additionally, because cigarette smoking is an important risk factor for lung cancer, and smokers tend to underestimate their risk of developing the disease $[27,28]$, we conducted subgroup analyses to examine the associations between family history and subjective risk perceptions among current smokers and former smokers, compared to never smokers. The specific hypotheses examined here were that individuals with a lung cancer family history would be more likely to perceive higher absolute and relative risks of developing lung cancer, and that these relationships would differ between never smokers and smokers (i.e. compared to never smokers, the association between family history and perceived risk of lung cancer would be less for smokers). 


\section{Materials and Methods}

\section{Sample}

Between February and August 2005, the National Cancer Institute conducted HINTS to assess U.S. adults' cancer-related information seeking, attitudes and behaviors. This survey also provided rich data with which to examine the associations between family history and cancer-related risk perceptions. The survey utilized a list-assisted random-digit-dial method to draw a random sample of telephone numbers in the United States; Black and Hispanic households were oversampled. One adult (age $\geq 18$ ) from each household was selected to be telephone-interviewed by trained interviewers in English or Spanish or to complete a webbased version of the survey. A total of 5,586 adults completed the survey. Response rates were $34 \%$ at the household screening level (i.e. initial contact with each household for sampling purposes) and $61 \%$ at the sampled person interview level [29]. This exempt study was approved by the National Institutes of Health's Office of Human Subjects Research and the University of North Florida's Institutional Review Board.

\section{Variable Definitions}

Absolute risk perception was measured by asking participants, on a 5-point Likert scale, 'How likely do you think it is that you will develop lung cancer in the future?' Response options ranged from very low to very high. For relative risk perception, participants were asked: 'Compared to the average person your age, would you say that you are 'more likely', 'about as likely' or 'less likely' to get lung cancer?' Family history of lung cancer was assessed with 2 questions: 'Have any of your family members ever had cancer?' and (if yes) 'What type of cancer was it?' Respondents answering 'yes' to the first question and 'lung cancer' to the second were considered to have a family history of lung cancer. Current smokers were those who had smoked at least 100 cigarettes in their lives and reported presently smoking 'every day' or 'some days.' Former smokers were defined as those who did not smoke at all currently but had smoked at least 100 cigarettes in their lifetimes. Individuals who had not smoked at least 100 cigarettes in their lives were classified as never smokers [27]. Based on variables described as associated with risk perceptions in the existing literature [e.g. 20,30], we also included potential covariates: age, gender, race/ethnicity, marital status, educational attainment, household income, perceived health status, health care coverage status, and use of various health information sources.

\section{Statistical Analysis}

Data were analyzed using SUDAAN version 9.0 (RTI International; Research Triangle Park, N.C.), incorporating the dataset replicate sampling weights [29]. We excluded respondents with a personal history of lung cancer and those who responded in Spanish, yielding a final sample size of 5,105. Fourteen responses were excluded from subgroup analyses due to missing items necessary to judge participants' smoking status. Accordingly, there were 2,627 never smokers, 1,507 former smokers and 958 current smokers. Descriptive statistics were examined for all variables. Bivariate differences by smoking status were examined using $\chi^{2}$ tests for categorical variables and one-way ANOVA tests for continuous variables. We first used univariate regression models to assess associations between family history of lung cancer and the risk perception variables. For multivariate analyses, we employed forward checking and backward elimination methods, based on Hosmer and Lemeshow [31], to determine which covariates to include in the final models using a $\mathrm{p}<0.20$ criterion for inclusion $[32,33]$. Both absolute and relative risk perceptions were treated as continuous variables in regression models. Statistical significance for studied associations between the independent and dependent variables was assessed as $\mathrm{p}<0.05$. We analyzed 3 subgroups of respondents based on smoking status (i.e. current, former and never smokers).

\section{Results}

\section{Sample Characteristics}

Approximately half of the respondents overall were female (52.5\%), highly educated ( $\geq$ college, $54.8 \%$ ) and had an annual household income greater than USD 50,000 (52.5\%), with a weighted mean age of 45.9 years. About $21.2 \%$ of respondents had a family history of lung cancer. Most respondents were white, non-Hispanic (75.6\%) and married or living with a partner (63.5\%). About $60 \%$ believed their health to be good, fair or poor and $87.5 \%$ had some kind of health care coverage.

As shown in table 1, we compared the differences in characteristics between current smokers, former smokers and never smokers. A higher proportion of current smokers reported a family history of lung cancer compared to former smokers and never smokers $(p=0.03)$. Additionally, smoking status was significantly associated with a number of variables, including age $(\mathrm{p}<0.0001)$, gender $(\mathrm{p}<0.001)$, marital status $(\mathrm{p}<0.0001)$, household income $(p<0.0001)$, educational attainment $(p<0.0001)$, perceived health status $(\mathrm{p}<0.0001)$, and health care coverage $(\mathrm{p}<0.0001)$.

\section{Absolute and Relative Risk Perceptions of Developing Lung Cancer}

A substantial proportion of respondents overall, as well as of never smokers and former smokers, perceived themselves to have a very low risk of developing lung cancer in the future $(47.0 \%, 66.3 \%, 40.4 \%$, respectively) and to be less likely to get lung cancer than other people the same age $(59.3 \%, 78.5 \%, 56.2 \%$, respectively). We examined differences in absolute and relative risk perceptions among current smokers, former smokers and never smokers. Both absolute $(\mathrm{p}<0.0001)$ and relative risk perceptions ( $p<0.0001)$ of developing lung cancer were significantly different by smoking status, with current smokers having the highest risk perceptions (table 2). 
Table 1. Characteristics of never smokers, former smokers, and current smokers among a representative sample of U.S. adults

\begin{tabular}{|c|c|c|c|c|c|c|c|}
\hline \multirow[t]{2}{*}{ Characteristics } & \multicolumn{2}{|c|}{$\begin{array}{l}\text { Never smokers } \\
(\mathrm{n}=2,627)\end{array}$} & \multicolumn{2}{|c|}{$\begin{array}{l}\text { Former smokers } \\
(\mathrm{n}=1,507)\end{array}$} & \multicolumn{2}{|c|}{$\begin{array}{l}\text { Current smokers } \\
(\mathrm{n}=958)\end{array}$} & \multirow{2}{*}{$\begin{array}{l}\text { Differences } \\
\text { by smoking } \\
\text { status } \\
\text { p value }\end{array}$} \\
\hline & $\mathrm{n}$ & $\%(95 \% \mathrm{CI})$ & $\mathrm{n}$ & $\%(95 \% \mathrm{CI})$ & $\mathrm{n}$ & $\%(95 \% \mathrm{CI})$ & \\
\hline Lung cancer family history & & & & & & & 0.03 \\
\hline Yes & 475 & $20.1(17.68-22.42)$ & 277 & $20.0(16.71-23.22)$ & 232 & $25.4(21.46-29.27)$ & \\
\hline No & 2,050 & $80.0(77.58-82.32)$ & 1,181 & $80.0(76.78-83.29)$ & 684 & $74.6(70.74-78.55)$ & \\
\hline Age & 2,621 & $44.0(0.3)^{\mathrm{a}}$ & 1,503 & $54.0(0.6)^{\mathrm{a}}$ & 954 & $41.0(0.6)^{\mathrm{a}}$ & $<0.0001$ \\
\hline Gender & & & & & & & $<0.001$ \\
\hline Male & 735 & $42.2(40.01-44.29)$ & 621 & $53.9(50.29-57.59)$ & 378 & $52.1(48.68-55.55)$ & \\
\hline Female & 1,892 & $57.9(55.71-60.00)$ & 886 & $46.1(42.41-49.71)$ & 580 & $47.9(44.45-51.32)$ & \\
\hline Race/ethnicity & & & & & & & 0.24 \\
\hline Non-Hispanic White & 2,085 & $74.7(72.56-76.74)$ & 1,273 & $79.7(76.39-82.95)$ & 722 & $73.6(69.52-77.71)$ & \\
\hline Non-Hispanic Black & 238 & $12.0(10.10-13.97)$ & 94 & $8.3(5.93-10.56)$ & 102 & $10.9(8.32-13.49)$ & \\
\hline Hispanic & 120 & $6.0(4.45-7.44)$ & 54 & $5.2(3.47-7.02)$ & 50 & $5.8(3.93-7.74)$ & \\
\hline Other & 147 & $7.4(5.67-9.07)$ & 73 & $6.8(4.22-9.47)$ & 76 & $9.7(6.49-12.81)$ & \\
\hline Marital status & & & & & & & $<0.0001$ \\
\hline Married/living with partner & 1,574 & $63.9(61.40-66.39)$ & 898 & $72.2(69.35-74.94)$ & 443 & $52.8(48.39-57.24)$ & \\
\hline Divorced/separated/widowed & 641 & $12.7(11.33-14.14)$ & 511 & $21.5(18.90-24.05)$ & 314 & $19.7(17.59-21.88)$ & \\
\hline Never been married & 402 & $23.4(20.56-26.18)$ & 91 & $6.4(4.51-8.25)$ & 198 & $27.5(23.56-31.35)$ & \\
\hline Household income, USD & & & & & & & $<0.0001$ \\
\hline$<25,000$ & 505 & $19.2(16.53-21.77)$ & 326 & $20.2(17.52-22.94)$ & 301 & $32.06(28.04-36.08)$ & \\
\hline $25,000-49,999$ & 568 & $22.6(19.75-25.43)$ & 342 & $27.3(23.70-30.86)$ & 244 & $28.43(24.19-32.66)$ & \\
\hline$\geq 50,000$ & 1,133 & $58.3(55.05-61.48)$ & 616 & $52.5(49.15-55.83)$ & 296 & $39.51(35.20-43.82)$ & \\
\hline Education & & & & & & & $<0.0001$ \\
\hline$\leq$ High school & 954 & $38.7(36.66-40.71)$ & 598 & $44.8(41.09-48.41)$ & 526 & $60.4(56.50-64.32)$ & \\
\hline$\geq$ College & 1,661 & $61.3(59.29-63.34)$ & 905 & $55.3(51.59-58.91)$ & 430 & $39.6(35.69-43.50)$ & \\
\hline Perceived health status & & & & & & & $<0.0001$ \\
\hline Excellent/very good & 1,301 & $47.1(44.72-49.43)$ & 688 & $44.3(40.70-47.94)$ & 305 & $31.2(27.05-35.28)$ & \\
\hline Good/fair/poor & 1,326 & $52.9(50.57-55.28)$ & 813 & $55.7(52.06-59.30)$ & 652 & $68.8(64.72-72.95)$ & \\
\hline Health care coverage & & & & & & & $<0.0001$ \\
\hline Yes & 2,426 & $90.8(88.96-92.69)$ & 1,403 & $90.7(88.00-93.46)$ & 774 & $76.3(72.30-80.28)$ & \\
\hline No & 193 & $9.2(7.31-11.04)$ & 101 & $9.3(6.54-12.00)$ & 181 & $23.7(19.72-27.70)$ & \\
\hline
\end{tabular}

${ }^{\text {a }}$ Mean (standard error).

Associations between Family History of Lung Cancer and Subjective Risk Perceptions

Figure 1 shows mean values for absolute subjective risk by family history based on smoking status. The scores for absolute risk perceptions of getting lung cancer ranged from 1 (perceived a very low likelihood to get lung cancer) to 5 (perceived a very high likelihood to get lung cancer). The average absolute risk perceptions for never smokers, former smokers and current smokers without a family history of lung cancer were $1.42,1.89$, and 3.16 , respectively. For those with a family history of lung cancer, their average absolute risk perceptions of acquiring lung cancer were higher (1.77 for never smokers, 2.07 for former smokers and 3.52 for current smokers). For relative risk perceptions of getting lung cancer, scores ranged from 1 (less likely to get lung cancer, compared to average people their age) to 3 (more likely to get lung cancer, compared to average people their age). Similar to the data for absolute risk perceptions, as seen in figure 2, never smokers with a family history of lung cancer had higher relative risk perceptions of getting lung cancer than those without a family history of lung cancer (1.36 vs. 1.21$)$. We also noticed similar patterns for former smokers (1.63 vs. 1.51) and current smokers (2.25 vs. 2.16).

We next conducted bivariate analyses. Having a family history of lung cancer was significantly and positively 


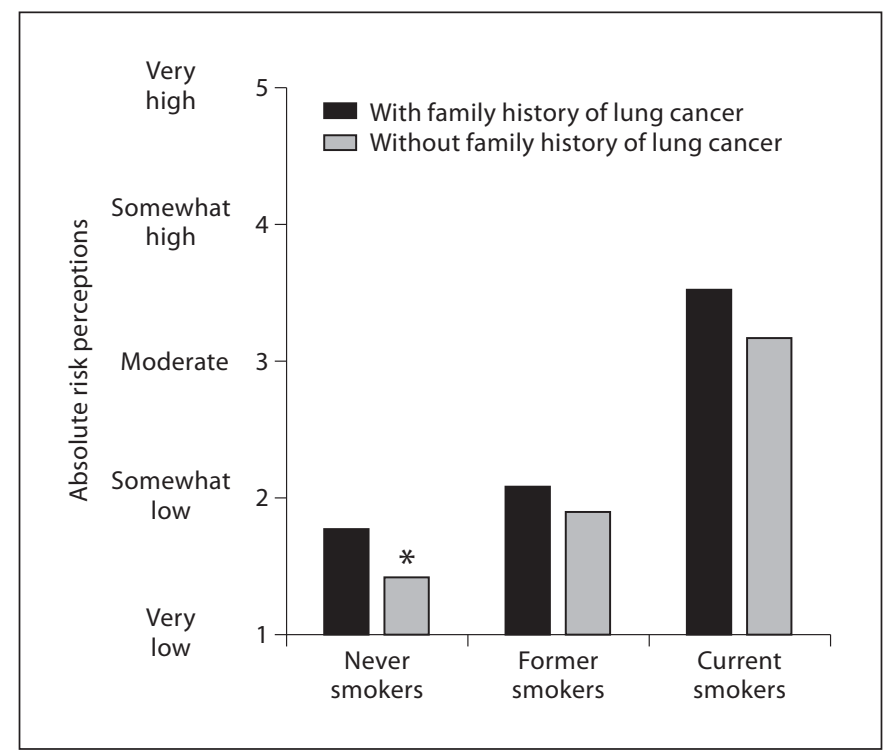

Fig. 1. Absolute risk perceptions for developing lung cancer, by family history of lung cancer and smoking status $\left({ }^{*} \mathrm{p}<0.05\right.$ in multivariate regression model after controlling for covariates).

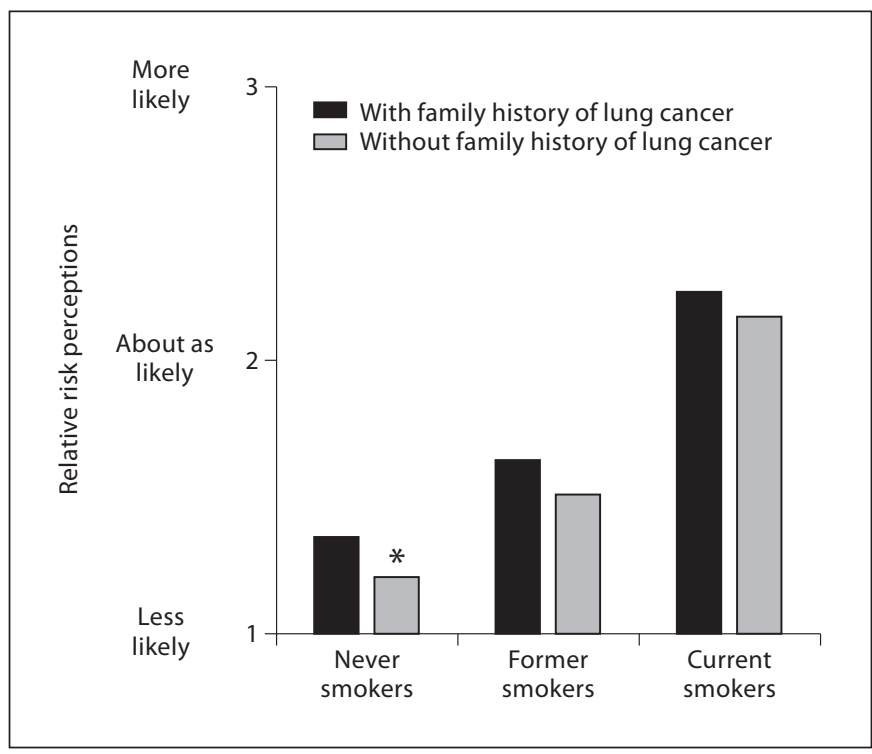

Fig. 2. Relative risk perceptions for developing lung cancer, by family history of lung cancer and smoking status $\left({ }^{*} \mathrm{p}<0.05\right.$ in multivariate regression model after controlling for covariates).

Table 2. Absolute and relative risk perceptions of developing lung cancer by smoking status

\begin{tabular}{|c|c|c|c|c|c|c|c|}
\hline \multirow[t]{2}{*}{ Variables } & \multicolumn{2}{|c|}{ Never smokers } & \multicolumn{2}{|c|}{ Former smokers } & \multicolumn{2}{|c|}{ Current smokers } & \multirow{2}{*}{$\begin{array}{l}\begin{array}{l}\text { Differences by } \\
\text { smoking status }\end{array} \\
\text { p value }\end{array}$} \\
\hline & $\mathrm{n}$ & $\%(95 \% \mathrm{CI})$ & $\mathrm{n}$ & $\%(95 \% \mathrm{CI})$ & $\mathrm{n}$ & $\%(95 \% \mathrm{CI})$ & \\
\hline \multicolumn{3}{|c|}{ Absolute risk perceptions } & & & & & $<0.0001$ \\
\hline Very low & 565 & $66.3(62.41-70.18)$ & 220 & $40.4(35.16-45.71)$ & 31 & $11.7(5.31-18.11)$ & \\
\hline Somewhat low & 169 & $21.0(17.78-24.19)$ & 150 & $33.3(26.70-39.98)$ & 36 & $14.6(7.03-22.09)$ & \\
\hline Very high & 8 & $0.7(0.00-1.42)$ & 6 & $1.5(0.00-3.05)$ & 42 & $14.5(8.55-20.52)$ & \\
\hline Total & 846 & & 497 & & 305 & & \\
\hline \multicolumn{3}{|c|}{ Relative risk perceptions } & & & & & $<0.0001$ \\
\hline Less likely & 652 & $78.5(74.39-82.58)$ & 281 & $56.2(50.82-61.51)$ & 63 & $20.7(14.84-26.57)$ & \\
\hline About as likely & 164 & $19.4(15.22-23.60)$ & 174 & $34.7(29.46-39.96)$ & 138 & $43.5(36.56-50.38)$ & \\
\hline
\end{tabular}

Note: Relative risk perceptions refer to 'compared to the average person your age'.

correlated to absolute and relative risk perceptions among all respondents $(\beta=0.42,95 \% \mathrm{CI}=0.21-0.64$ for absolute risk perceptions; $\beta=0.18,95 \% \mathrm{CI}=0.04-0.33$ for relative risk perceptions) and never smokers $(\beta=0.36,95 \% \mathrm{CI}=$ $0.10-0.62$ for absolute risk perceptions; $\beta=0.14,95 \%$
$\mathrm{CI}=0.03-0.25$ for relative risk perceptions). However, family history of lung cancer was not associated with either absolute risk perceptions or relative risk perceptions of developing lung cancer among former smokers $(\beta=$ $0.17,95 \% \mathrm{CI}=-0.07-0.41$ for absolute risk perceptions; 
$\beta=0.12,95 \% \mathrm{CI}=-0.07-0.31$ for relative risk perceptions) and current smokers ( $\beta=0.35,95 \% \mathrm{CI}=-0.11-82$ for absolute risk perceptions; $\beta=0.09,95 \% \mathrm{CI}=-0.23$ 0.42 for relative risk perceptions).

After controlling for covariates in multivariate regression models, family history of lung cancer remained positively associated with absolute and relative risk perceptions among all respondents $(\beta=0.33,95 \% \mathrm{CI}=0.16-0.51$ for absolute risk perceptions; $\beta=0.12,95 \% \mathrm{CI}=0.0004$ 0.23 for relative risk perceptions) and never smokers ( $\beta=$ $0.40,95 \% \mathrm{CI}=0.14-0.67$ for absolute risk perceptions; $\beta=0.14,95 \% \mathrm{CI}=0.01-0.27$ for relative risk perceptions). Yet, lung cancer family history was not significantly associated with subjective risk perceptions among current smokers $(\beta=0.41,95 \% \mathrm{CI}=-0.03-0.85$ for absolute risk perceptions; $\beta=0.24,95 \% \mathrm{CI}=-0.06-0.53$ for relative risk perceptions) and former smokers $(\beta=0.14,95 \% \mathrm{CI}=$ $-0.09-0.38$ for absolute risk perceptions; $\beta=0.10,95 \%$ $\mathrm{CI}=-0.10-0.29$ for relative risk perceptions).

\section{Discussion}

Previous studies have documented that family history is linked to people's objective risk of developing lung cancer, irrespective of smoking status. Yet, the relationship between family history and subjective risk perceptions, which is critical to the design of prevention and intervention messages, is unknown. This study analyzed a large national dataset with a representative sample of U.S. adults to assess the associations between self-reported lung cancer family history and subjective risk perceptions. The results demonstrated that self-reported family history of lung cancer was significantly related to both absolute and relative risk perceptions among respondents overall. While findings regarding a relationship between family history and subjective risk perceptions have been inconsistent for other types of cancers [19-24], our findings are consistent with those of Stark et al. [19] and Mouchawar et al. [24], which suggested that family history information was related to people's perceived risk of developing colorectal and breast cancers.

It is important to notice that the interpretation of this association became more nuanced when we stratified respondents into 3 groups based on their smoking status; the associations between family history of lung cancer and risk perceptions were significant for never smokers only. Interestingly, for current and former smokers, having a family history of lung cancer was not associated with their perceived risk. One potential explanation for

Risk Perceptions and Lung Cancer Family History these results is that smokers tend to inaccurately estimate their risk of developing lung cancer $[27,28]$. Weinstein [34] reviewed studies exploring smokers' risk perceptions and concluded that smokers are likely to minimize their own health risk. An analysis of data from the 2003 HINTS wave also indicated that smokers underestimate their risk of lung cancer [27]. Current and former smokers might also base their subjective risk perceptions primarily on their smoking behaviors rather than their family history.

The findings reported here could have important implications for the integration of family history information into cancer prevention and control programs, which has been recommended by leading health agencies [35, $36]$ and researchers $[37,38]$. For example, the federal government is currently promoting 'My Family Health Portrait' - a useful genomic tool developed by the Surgeon General - to the entire U.S. population [39]. However, understanding how the lay public perceives its risk, and whether these perceptions vary based on family history, is critical to the successful implementation of such efforts. Specifically, the results presented here indicate that, even though all people with a family history of lung cancer could be considered as at increased risk, only never smokers actually linked their family history to having a heightened risk for developing lung cancer. In contrast, current or former smokers did not seem to recognize this association. Therefore, family history-based prevention and control messages might be interpreted as intended by never smokers but not by former and current smokers who are critical populations to reach with such efforts.

These results then highlight an important issue that could greatly affect the clinical utility of lung cancer family history information. Health professionals cannot assume that current and former smokers with a family history of lung cancer will perceive themselves to be at greater risk for lung cancer than those who do not have this family history, and, therefore, that they will respond to prevention or cessation messages based on family history accordingly. Despite research showing that family history of lung cancer is associated with objective risk of developing lung cancer, current or former smokers with a family history of lung cancer might not integrate their family history into their risk perceptions. Research is warranted to explore whether educational information regarding the link between family history and lung cancer risk can affect these risk perceptions.

These results also have broader implications for a number of possible prevention or intervention efforts. Family history has been proposed as an initial criterion to classify individuals' disease risk in order to make indi- 
vidualized preventive recommendations, including possible genetic susceptibility testing [2]. Polymorphisms in the genes GSTM1, CYP2D6, and L-myc have been related to lung cancer development $[9,40]$; recent studies have found that specific nicotinic acetylcholine receptor genes on chromosome $15 \mathrm{q} 24$ also contribute to lung cancer risk [41-43]. Private companies, such as 23andMe [44], already sell lung cancer genetic susceptibility testing directly to consumers. However, although such genetic tests may hold potential in disease prevention efforts, it is unclear how current and former smokers might interpret such a test based on inherited risk for lung cancer. For example, if smokers with a family history of lung cancer do not perceive the disease as having an inherited risk component, would they be willing to take genetic susceptibility tests? If yes, would they understand their test results and see value in genetic testing for lung cancer?

Similarly, although this issue remains under debate, spiral computed tomography screening and chest radiography have been recommended as measures for early detection of lung cancer among high-risk populations, such as those with a family history of lung cancer [3, 4, 45]. However, it is unclear whether having a family history of lung cancer might motivate smokers with this family history to undergo such screening. Given the observed lack of association between family history and risk perceptions for current and former smokers, the relationship between family history and uptake of other screening and health behaviors should be further explored.

Lastly, various health behavior theories have suggested that if people have higher risk perceptions for a certain disease, they will be more likely to adopt related preventive health behaviors. Other emotion-based (or parallel process) theories indicate that smoking behaviors could lower risk perceptions. Seeking to overcome those lower risk perceptions might exacerbate smoking behaviors via enhancing fear [18]. Limited studies have examined the specific relationship between risk perceptions and actual smoking behaviors, but the former theories are supported by Liu and Hsieh [46], who analyzed Taiwanese survey data with 812 responses and reported that people with higher lung cancer risk perceptions had lower smoking probability. Similarly, Magnan et al. [47] randomly assigned smokers to 2 groups (i.e. carrying a PDA to read daily statements about smoking consequences or daily hassles) and found that, compared to the other group, those who read about smoking consequences perceived higher risk and worry of getting a medical condition. Additionally, such heightened risk perceptions and worry increased their motivation to quit smoking. Because risk perceptions play a significant role in preventive health behavior, our study suggests that if current and former smokers do not link their family history to a greater risk of getting lung cancer, family history-based information might not increase their motivation to engage in preventive behaviors (e.g. cessation and reduction of environmental tobacco smoke).

The limitations of this analysis should be considered in interpreting our findings. First, as this was a secondary data analysis, we were limited to using only questions included on the survey. Asking respondents whether they had a family history of lung cancer directly might have yielded different data than asking respondents whether they had any family members that had been diagnosed with cancer and what type. Additionally, having a family history of lung cancer was based on whether any family members had ever had lung cancer. Subjective risk could conceivably vary if family history responses were based on first-degree relatives compared to more distant relatives. Further, it is possible that error variance in this measure was random across different smoking status groups or that there might be a higher incidence of first-degree family history of lung cancer among current or former smokers than never smokers. Future studies could explore whether different definitions of family history would affect people's perceived risk of lung cancer. Moreover, the cross-sectional nature of the data meant that we could not examine the direction of causality for observed associations. Lastly, it may be that we did not observe a statistically significant relationship between family history of lung cancer and subjective risk perceptions among current smokers due to the higher variance and smaller sample size for this group. Researchers and practitioners should take this limitation into account before applying our findings. Future studies could examine the association between family history of lung cancer and risk perceptions among a larger sample of current smokers.

In this study, we have examined one issue that has the potential to substantially impact the effectiveness of lung cancer prevention and control programs based on family history information: how individuals view the link between family history and lung cancer risk. The purpose of this analysis was not to directly test the clinical utility of family history information in these programs, although we think our findings have related implications. Rather, we would like to initiate a dialog among multidisciplinary scholars to consider the meaning of family history in lung cancer prevention and intervention programs. We believe that this examination of the associa- 
tion between risk perceptions and family history serves as a beginning for future research in this area and that the outcomes of such research will lead to more effective prevention and control programs for lung cancer.

In summary, the findings presented here suggest that efforts in the prevention of lung cancer might need to explicitly educate individuals about the importance of family history in lung cancer risk. Family history information might have the potential to help target individuals who are at increased risk due to their family history with preventive interventions. However, additional intervention research is needed to examine how health education and promotion programs emphasizing the link between family history and lung cancer risk could be implemented without stigmatizing those at increased risk or substantially increasing their anxiety and worry.

\section{Acknowledgements}

This research was supported by the Intramural Research Program of the National Human Genome Research Institute, National Institutes of Health. We thank Cristofer Price, Julie Williams, and Sonju Harris at Abt Associates Inc. for providing statistical support and Colleen McBride at the National Human Genome Research Institute for providing valuable input on an earlier draft of this paper.

\section{References}

1 American Lung Association: Lung cancer fact sheet. 2007. Available at http://www. lungusa.org/site/apps/nlnet/content3.aspx? $c=d v L U K 9 O 0 E \& b=4294229 \& c t=3232839$.

$\checkmark 2$ Yoon PW, Scheuner MT, Peterson-Oehlke KL, Gwinn M, Faucett A, Khoury MJ: Can family history be used as a tool for public health and preventive medicine? Genet Med 2002;4:304-310.

$\checkmark 3$ Schwartz AG. Lung cancer: family history matters. Chest 2006;130:936-937.

$\checkmark 4$ Schwartz AG, Ruckdeschel JC: Familial lung cancer: genetic susceptibility and relationship to chronic obstructive pulmonary disease. Am J Respir Crit Care Med 2006;173 $16-22$.

$>5$ Thorne SL, Malarcher A, Maurice E, Caraballo R: Cigarette smoking among adults United States, 2007. MMWR 2008;57:12211226.

6 McBride CM, Bepler G, Lipkus IM, Lyna P, Samsa G, Albright J, Datta S, Rimer BK: Incorporating genetic susceptibility feedback into a smoking cessation program for African-American smokers with low income. Cancer Epidemiol Biomarkers Prev 2002;11: 521-528.

7 Sanderson SC, Humphries SE, Hubbart C, Hughes E, Jarvis MJ, Wardle J: Psychological and behavioural impact of genetic testing smokers for lung cancer risk: a phase II exploratory trial. J Health Psychol 2008; 13: 481-494.

$>8$ Lerman C, Gold K, Audrain J, Lin TH, Boyd NR, Orleans CT, Wilfond B, Louben G, Caporaso $\mathrm{N}$ : Incorporating biomarkers of exposure and genetic susceptibility into smoking cessation treatment: effects on smoking-related cognitions, emotions, and behavior change. Health Psychol 1997;16: 87-99.
9 Ito H, Matsuo K, Wakai K, Saito T, Kumimoto H, Okuma K, Tajima K, Hamajima N: An intervention study of smoking cessation with feedback on genetic cancer susceptibility in Japan. Prev Med 2006;42:102-108.

10 Audrain J, Boyd NR, Roth J, Main D, Caporaso NF, Lerman C: Genetic susceptibility testing in smoking-cessation treatment: oneyear outcomes of a randomized trial. Addict Behav 1997;22:741-751.

11 Yoon PW, Scheuner MT, Khoury MJ: Research priorities for evaluating family history in the prevention of common chronic diseases Am J Prev Med 2003;24:128-135.

12 Matakidou A, Eisen T, Houlston RS: Systematic review of the relationship between family history and lung cancer risk. Br J Cancer 2005;93:825-833.

13 Janz NK, Champion VL, Strecher VJ: The health belief model; in Glanz K, Rimer BK, Lewis FM (eds): Health Behavior and Health Education, ed 3. San Francisco, John Wiley \& Sons Inc., 2002, pp 45-66.

14 Leventhal, H, Meyer, D, Nerenz, D: The common sense representation of illness danger; in Rachman, S. (ed): Contribution to Medical Psychology. Oxford, Pergamon Press, 1980, pp 7-30.

15 Rimal RN, Real K: Perceived risk and efficacy beliefs as motivators of change: use of the risk perception attitude (RPA) framework to understand health behaviors. Hum Commun Res 2003;29:370-399.

16 Rogers RW: A protection motivation theory of fear appeals and attitude change. J Psychol 1975;91:93-114.

17 Ajzen I, Fischbein M: Understanding Attitudes and Predicting Behavior. Englewood Cliffs, Prentice-Hall, 1980.

18 Witte K, Meyer G, Martell D: Effective Health Risk Messages: A Step-by-Step Guide. Thousand Oaks, Sage Publications Inc., 2001.
19 Stark JR, Bertone-Johnson ER, Costanza ME, Stoddard AM: Factors associated with colorectal cancer risk perception: the role of polyps and family history. Health Educ Res 2006;21:740-749.

20 Bloom JR, Stewart SL, Oakley-Girvans I, Banks PJ, Chang S: Family history, perceived risk, and prostate cancer screening among African American men. Cancer Epidemiol Biomarkers Prev 2006;15:2167-2173.

21 Aiken LS, Fenaughty AM, West SG, Johnson JJ, Luckett TL: Perceived determinants of risk for breast cancer and the relations among objective risk, perceived risk, and screening behavior over time. Womens Health 1995;1:27-50.

22 Evans DG, Burnell LD, Hopwood P, Howell A: Perception of risk in women with a family history of breast cancer. Br J Cancer 1993;67: 612-614.

-23 Watson M, Duvivier V, Wade Walsh M, Ashley S, Davidson J, Papaikonomou M, Murday V, Sacks N, Eeles R: Family history of breast cancer: what do women understand and recall about their genetic risk? J Med Genet 1998;35:731-738.

24 Mouchawar J, Byers T, Cutter G, Dignan M, Michael S: A study of the relationship between family history of breast cancer and knowledge of breast cancer genetic testing prerequisites. Cancer Detect Prev 1999;23: 22-30.

25 Lipkus IM, Kuchibhatla M, McBride CM, Bosworth HB, Pollak KI, Siegler IC, Rimer BK: Relationships among breast cancer perceived absolute risk, comparative risk, and worries. Cancer Epidemiol Biomarkers Prev 2000;9:973-975.

26 Orom H, Cote ML, Gonzalez HM, Underwood W, 3rd, Schwartz AG: Family history of cancer: is it an accurate indicator of cancer risk in the immigrant population? Cancer 2008;112:399-406. 
27 Weinstein ND, Marcus SE, Moser RP: Smokers' unrealistic optimism about their risk. Tob Control 2005;14:55-59.

-28 McCoy SB, Gibbons FX, Reis TJ, Gerrard M, Luus CA, Sufka AV: Perceptions of smoking risk as a function of smoking status. J Behav Med 1992;15:469-488.

29 National Cancer Institute: HINTS. 2007. Available at http://hints.cancer.gov/.

30 Morton TA, Duck JM: Communication and health beliefs: mass and interpersonal influences on perceptions of risk to self and others. Communication Research 2001;28:602626.

31 Hosmer DW, Lemeshow S: Applied Logistic Regression. New York, John Wiley \& Sons Inc., 2000.

32 Maldonado G, Greenland S: Simulation study of confounder-selection strategies. Am J Epidemiol 1993;138:923-936.

-33 Budtz-Jorgensen E, Keilding N, Grandjean P, Weihe P: Confounder selection in environmental epidemiology: assessment of health effects of prenatal mercury exposure. Ann Epidemiol 2007;17:27-35.

-34 Weinstein ND: Accuracy of smokers' risk perceptions. Ann Behav Med 1998;20:135140.

35 National Human Genome Research Institute: Family history initiative. 2007 Available at http://www.genome.gov/17516481.

36 The Centers for Disease Control and Prevention: Family history public health initiative. 2007. Available at http://www.cdc.gov/ genomics/famhistory/famhist.htm.
7 Ramsey SD, Yoon P, Moonesinghe R, Khoury MJ: Population-based study of the prevalence of family history of cancer: implications for cancer screening and prevention. Genet Med 2006;8:571-575.

38 Guttmacher AE, Collins FS, Carmona RH: The family history - more important than ever. N Engl J Med 2004;351:2333-2336.

39 The Surgeon General: My family health portrait. 2009. Available at https://familyhistory. hhs.gov/fhh-web/home.action.

40 Khoury MJ, Burke W, Thomson EJ: Genetics and Public Health in the 21st Century. New York, Oxford University Press, 2000.

41 Amos CI, Wu X, Broderick P, Gorlov IP, Gu J, Eisen T, Dong Q, Zhang Q, Gu X, Vijayakrishnan J, Sullivan K, Matakidou A, Wang Y, Mills G, Doheny K, Tsai YY, Chen WV, Shete S, Spitz MR, Houlston RS: Genome-wide association scan of tag SNPs identifies a susceptibility locus for lung cancer at 15q25.1. Nat Genet 2008;40:616-622.

42 Hung RJ, McKay JD, Gaborieau V, Boffetta P, Hashibe M, Zaridze D, Mukeria A, Szeszenia-Dabrowska N, Lissowska J, Rudnai P, Fabianova E, Mates D, Bencko V, Foretova L, Janout V, Chen C, Goodman G, Field JK, Liloglou T, Xinarianos G, Cassidy A, McLaughlin J, Liu G, Narod S, Krokan HE, Skorpen F, Elvestad MB, Hveem K, Vatten L, Linseisen J, Clavel-Chapelon F, Vineis $\mathrm{P}$, Bueno-de-Mesquita HB, Lund E, Martinez C, Bingham S, Rasmuson T, Hainaut P, Riboli E, Ahrens W, Benhamou S, Lagiou P, Trichopoulos D, Holcatova I, Merletti F, Kjaerheim K, Agudo A, Macfarlane G, Talamini R, Simonato L, Lowry R, Conway DI, Znaor A, Healy C, Zelenika D, Boland A, Delepine M, Foglio M, Lechner D, Matsuda F, Blanche H, Gut I, Heath S, Lathrop M, Brennan P: A susceptibility locus for lung cancer maps to nicotinic acetylcholine receptor subunit genes on $15 q 25$. Nature 2008; 452:633-637.
3 Thorgeirsson TE, Geller F, Sulem P, Rafnar T, Wiste A, Magnusson KP, Manolescu A, Thorleifsson $G$, Stefansson $H$, Ingason $A$, Stacey SN, Bergthorsson JT, Thorlacius S, Gudmundsson J, Jonsson T, Jakobsdottir M, Saemundsdottir J, Olafsdottir O, Gudmundsson LJ, Bjornsdottir G, Kristjansson $\mathrm{K}$, Skuladottir H, Isaksson HJ, Gudbjartsson T, Jones GT, Mueller T, Gottsater A, Flex A, Aben KK, de Vegt F, Mulders PF, Isla D, Vidal MJ, Asin L, Saez B, Murillo L, Blondal T, Kolbeinsson H, Stefansson JG, Hansdottir I, Runarsdottir V, Pola R, Lindblad B, van Rij AM, Dieplinger B, Haltmayer M, Mayordomo JI, Kiemeney LA, Matthiasson SE, Oskarsson $\mathrm{H}$, Tyrfingsson T, Gudbjartsson DF, Gulcher JR, Jonsson S, Thorsteinsdottir U, Kong A, Stefansson K: A variant associated with nicotine dependence, lung cancer and peripheral arterial disease. Nature 2008;452: 638-642.

44 23andMe: Genetics just got personal. 2008. Available at https://www.23andme.com.

-45 Marcy TW, Stefanek M, Thompson KM: Genetic testing for lung cancer risk: if physicians can do it, should they? J Gen Intern Med 2002;17:946-951.

46 Liu JT, Hsieh CR: Risk perception and smoking behavior: evidence from Taiwan. J Risk Uncertain 1995;11:139-157.

47 Magnan RE, Köblitz AR, Zielke DJ, McCaul KD: The effects of warning smokers on perceived risk, worry, and motivation to quit. Ann Behav Med 2009;37:46-57. 